\title{
EXPERIMENTAL INVESTIGATION ON TORSION BAR SUSPENSION SYSTEM USING E- GLASS FIBRE REINFORCED COMPOSITE
} MATERIAL

\author{
M. Manikandan ${ }^{1}$, K. Raja ${ }^{2}$, V.S. Chandrasekar ${ }^{3}$ \\ ${ }^{1} P G$ scholar, Department of Mechanical Engineering, Anna University, Regional Office, Madurai \\ ${ }^{2}$ Professor, Department of Mechanical Engineering, University College of Engineering, Ramanathapuram \\ ${ }^{3}$ Assistant professor, Department of Mechanical Engineering, University College of Engineering, Ramanathapuram
}

\begin{abstract}
The purpose of this study is to investigate torsion deflections and energy storage of the composite bar in torsion bar suspension system. In this experimental study, round solid steel bar is machined and wounded with E-Glass/ Epoxy were manufactured by filament winding process. The experiment was carried out on a torsion test machine, which was built specifically to investigate the static and dynamic characteristics of torsion spring bar used in vehicle suspension system. This paper provides fundamental knowledge of torsion test and significant parameters such as torque, modulus of resilience in torsion and angle of twist has been highlighted. The torsion deflections were obtained experimentally. The results of experimental study are compared with the conventional torsion suspension system.
\end{abstract}

Keywords: E-Glass/Epoxy, Resilience, Torsion bar

\section{INTRODUCTION}

The role of a suspension system is to support the vehicle weight, to isolate the vehicle body from road disturbances, and to maintain the traction force between the tire and the road surface. The purpose of suspension system is to improve the ride comfort, road handling and stability of vehicles. For vehicle suspension system design, it is always challenging to maintain simultaneously a high standard of ride, handling, and body attitude control under all driving conditions.

The problems stem from the wide range of operating conditions created by varying road conditions, vehicle speed, and load. In general, during cornering, braking, and bumping, a high stiffness and damping is needed to provide good handling properties, and to satisfy workspace limitations of the suspension system [1].

However, when a vehicle runs on a low roughness road, a suspension system with low stiffness and damping is needed for good ride comfort. The performance are depends on stiffness and strength properties. The high limit strains and low weight of fiber reinforced plastics (FRP) appear attractive.

This work investigates the potential of composite material as reinforced E-GLASS fiber with steel in a torsion bar suspension system.

\subsection{Literature Review}

It becomes more difficult to find spring and damper characteristics to achieve an acceptable compromise between ride comfort and handling. For vehicles that require both good on- and off-road capabilities, suspension design poses a significant challenge. The use of an active anti-roll bar as a means of improving the handling of an off-road vehicle without sacrificing ride comfort [2]

Torsion bar springs are dynamically loaded machine elements which can break due to fatigue. Using twist angle, it is possible to increase the elastic-plastic pre-setting of a torsion bar. A spring made as a torsion bar may exhibit different fatigue behaviour regarding to different elastic plastic pre-setting torques. The established model provides the possibility for optimizing a spring design in terms of size (e.g. weight) of the spring [3].

Anti-roll bars used in ground vehicle to reduce body roll by resisting any uneven vertical motion between the pair of wheels suffer from fatigue failure. The result of FE analyses indicated that equivalent stress in the inner surface of the corner bend was the maximum; wherein the shear stress dominates. It was concluded that the reduction of equivalent stress in anti-roll bar accomplished by modifying the bushing provided a significant improvement in the fatigue life [4].

A new composite semi-elliptical suspension spring by utilizing fibre reinforced composite strength in principal direction instead of shear direction. The results showed that the fibre type and ellipticity ratio significantly influenced the spring stiffness. Ellipticity ratio significantly affected the resilience energy absorption capability of composite elliptical tubes. The carbon-glass/epoxy elliptical springs 
exhibited higher spring rate but poor ride quality compared with the non-hybrid one [5]

\subsection{Problem Identification}

Automotive suspension systems provide compliant connections between vehicle body structures and wheel axles. They play a key role in determining the vibration and handling of a vehicle. Due to dynamic deflections of a vehicle which is travelled in a rough roads cause the performance loss and also reduce the lifetime of systems connected with the suspension system [6].

The suspension control arm of the passenger car is subjected to loads and consequently stresses of a high magnitude. The design for this component poses a challenge to an engineer. While this component integrates with the suspension system of the vehicle, the lower arm takes up the load during the ride [7].

Failure of this component during the ride could jeopardize the suspension system and could lead to accident including risk of life or injury [8].

\section{MATERIALS, METHODS AND DIMENSIONS}

The conventional torsion bar is made up of medium carbon alloy used where the high stressed parts required, which is of AISI 4140/ 4340 steel material. The chemical composition of the AISI 4140/ 4340 steels are given in Table 1.

Table - 1: \% chemical composition of AISI 4140/4340 Steel

\begin{tabular}{|l|l|l|l|l|l|l|l|}
\hline & $\mathrm{C}$ & $\mathrm{Mn}$ & $\mathrm{P}$ & $\mathrm{S}$ & $\mathrm{Si}$ & $\mathrm{Cr}$ & $\mathrm{Mo}$ \\
\hline $\begin{array}{l}\text { AISI } \\
4140\end{array}$ & 0.38 & 0.75 & 0.035 & 0.04 & 0.15 & 0.80 & 0.15 \\
\hline $\begin{array}{l}\text { AISI } \\
4340\end{array}$ & 0.43 & 0.80 & 0.035 & 0.04 & 0.30 & 1.65 & 0.3 \\
\hline
\end{tabular}

The conventional steel bar (AISI 410/ 4340) is reinforced with E-Glass fibre (GFRP) which is coated with the Epoxy resin to form as a perfect solid bar. The chemical composition of E-Glass is shown in Table 2.

Table - 2:\% chemical composition of E-Glass Fibre

\begin{tabular}{|l|l|l|l|l|l|l|}
\hline $\mathrm{SiO}_{2}$ & $\mathrm{Al}_{2} \mathrm{O}_{3}$ & $\mathrm{CaO}+\mathrm{MgO}$ & $\mathrm{B}_{2} \mathrm{O}_{3}$ & $\mathrm{~F}_{2}$ & $\begin{array}{l}\mathrm{Na}_{2} \mathrm{O}+ \\
\mathrm{K}_{2} \mathrm{O}\end{array}$ & $\mathrm{Fe}_{2} \mathrm{O}_{3}$ \\
\hline 55 & 15 & 26 & 8 & 0.6 & 1 & 0.5 \\
\hline
\end{tabular}

The diameter of the torsion bar is $254 \mathrm{~mm}$ and length is $1000 \mathrm{~mm}$.

The main goal is to obtain the desired value of resilience available in the composite suspension system (steel and eglass fiber with ratio of constituent matrix) which would define experimentally. Nowadays composite materials deal with the various applications in mechanical industries. And the major composite materials and its properties are studied and implement the required material to improve the performance of the torsion bar suspension system. The required parameters are to be tested and identified experimentally; some are resilience and stiffness from the torque - twist diagram. The sizing of torsion bars with circular cross section one finds in engineering handbooks the formulae for the applied torque $T$,

$$
\mathrm{T}=\frac{\pi}{16} d^{3} \tau
$$

The stiffness is calculated by $\mathrm{k}$,

$$
\mathrm{k}=\frac{\pi d^{3}}{32 l} G
$$

The stiffness relating torque and angle of deflection for an unit length [9].

$$
\theta=\frac{T}{k}
$$

Resilience is the ability of a material to absorb energy when it is deformed elastically, and release that energy upon unloading. The modulus of resilience is defined as the maximum energy that can be absorbed per unit volume without creating a permanent distortion. It can be calculated by integrating the stress - strain curve from zero to the elastic limit. In uniaxial tension,

$$
\mathrm{U}_{\mathrm{r}}=\frac{\sigma_{y}^{2}}{2 E}
$$

Where $\mathrm{U}_{\mathrm{r}}$ is the modulus of resilience,

$\sigma_{\mathrm{y}}$ is the yield strength,

$\mathrm{E}$ is the young's modulus.

The mechanical properties of the material required for the torsion bar is discussed in Table 3 .

Table -3: Mechanical properties of composite Steel/ E-glass

\begin{tabular}{|l|l|l|l|l|}
\hline Material & $\mathrm{E}(\mathrm{GPa})$ & $\mathrm{G}(\mathrm{GPa})$ & $\rho\left(\mathrm{g} / \mathrm{cm}^{3}\right)$ & $\begin{array}{l}\text { Poisson } \\
\text { ratio }\end{array}$ \\
\hline Steel & 200 & 85 & 7.85 & 0.3 \\
\hline E-Glass & 80 & 30 & 2.58 & 0.23 \\
\hline Epoxy & 3.5 & 1.3 & 1.54 & 0.33 \\
\hline
\end{tabular}

The specimen used here is a reinforced composite material of Steel and E-Glass fibre coated with Epoxy resin, which is wounded by using a filament winding technique [10].

\section{EXPERIMENTAL STUDY}

The experimental study is prepared according to the standard of ASTM E143-01 testing method, standard test method for identifying torsion deflections at room temperature. The machine setup is used to identify the applied torque and angle of twist are recorded simultaneously. When the applied loadings are shearin nature, shear rigidity and yield strength are to be known in order to apply the closed form of equation commonly used in engineering analysis. These properties are determined from the recorded values, which is most commonly measurement for the torsion testing of a solid bar. 
The energy diagram or modulus of resilience is used to construct from the torque- twist diagram, while the yield strength is obtained from the torque- twist diagram, which is of similar to the shear stress - strain diagram. The yield strength is identified by means of setting $2 \%$ offset of stress - strain diagram(torque- twist diagram) and the calculation of this area described the yield strength of the specimen. The parameter angle of twist is identified upto the corresponding load ie., twisting moment ranges between $10-12$ kN.m obtained by a vehicle.

\section{RESULTS AND DISCUSSIONS}

The data measured from the torsion testing was used to calculate the maximum energy, the composite torsion bar which can be absorbed or retrieved when the twisting load is released.

The table shows the value of steel AISI 4140/4340 torsion bar exhibited upto its yield point, where the stiffness of the bar which is calculated from the data is

$$
\mathrm{k}=50 \mathrm{kN} / \mathrm{m} \text { (approx. value) }
$$

Table - 4: Experimental results of conventional steel bar

\begin{tabular}{|l|ll|l|l|}
\hline Sl. No & $\begin{array}{l}\text { Angle } \\
\text { deflection } \\
\text { deg) }\end{array}$ & $\begin{array}{l}\text { of } \\
(\circ)\end{array}$ & Twisting & Resilience (J) \\
\hline 1 & 0 & 0 & 0 \\
\hline 2 & 2 & 1750 & 30.46 \\
\hline 3 & 4 & 3500 & 121.85 \\
\hline 4 & 6 & 5240 & 274.16 \\
\hline 5 & 8 & 7000 & 487.39 \\
\hline 6 & 10 & 8730 & 761.54 \\
\hline 7 & 12 & 10450 & 1096.62 \\
\hline
\end{tabular}

Performance of AISI 4140/4340 steel are identified experimentally, the torque - twist diagram are shown below,

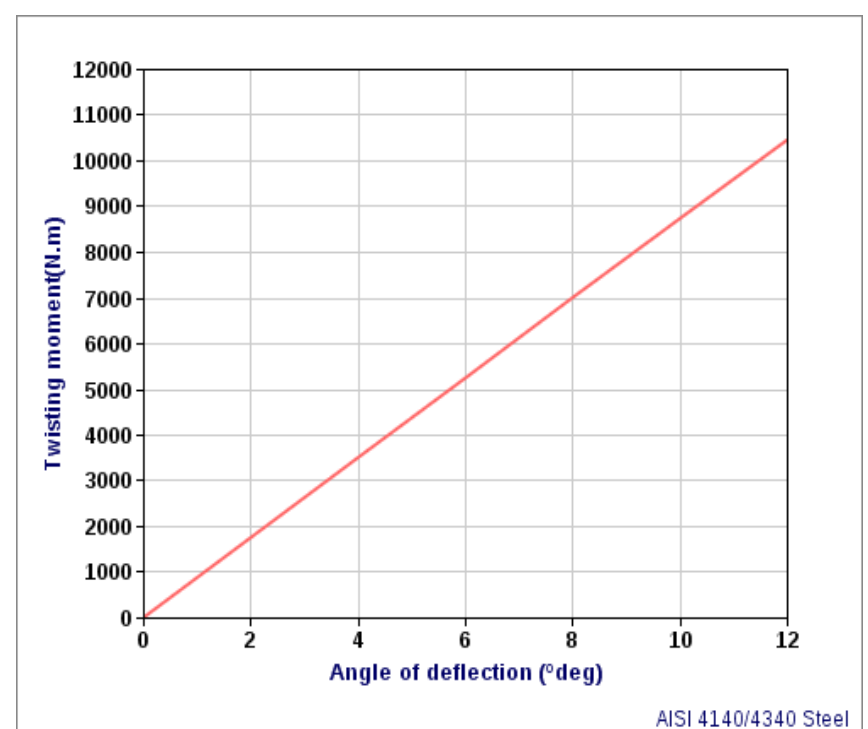

Fig - 1: Torque- twist diagram of conventional steel bar
The table shows the value exhibited by a material made of steel/ E-glass composite fibre having its higher yield point, the stiffness of this specimen is $\mathrm{k}=57 \mathrm{kN} / \mathrm{m}$

Table - 5: Experimental results of composite torsion bar

\begin{tabular}{|l|ll|l|}
\hline Sl. No & $\begin{array}{l}\text { Angle of Twisting } \\
\text { deflection } \\
\text { deg) }\end{array}$ & $\begin{array}{l}\text { Modulus of } \\
\text { resilience (J) } \\
(\text { N.m) }\end{array}$ \\
\hline 1 & 0 & 0 & 0 \\
\hline 2 & 2 & 2010 & 35.11 \\
\hline 3 & 4 & 4040 & 140.47 \\
\hline 4 & 6 & 6050 & 316.06 \\
\hline 5 & 8 & 8070 & 561.88 \\
\hline 6 & 10 & 10060 & 877.94 \\
\hline 7 & 12 & 12072 & 1264.23 \\
\hline
\end{tabular}

Performance of reinforced composite material steel/ e-glass fibre are determined experimentally, the torque - twist diagram is shown below,

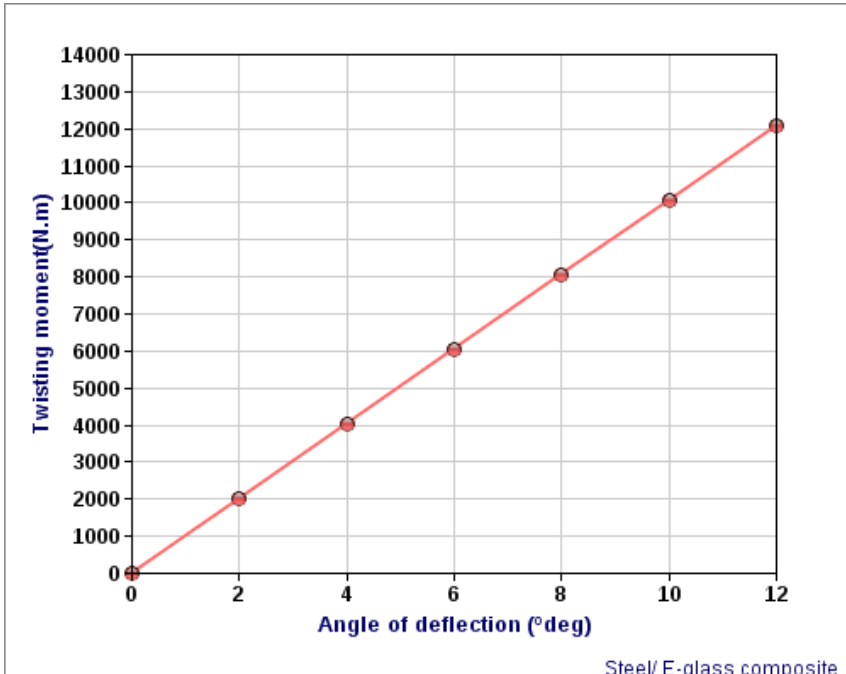

Fig - 2: Torque-twist diagram of composite torsion bar

Comparison is based on the performance of AISI 4140/4340 steel and E-glass composite fibre material are identified experimentally, the torque- twist diagram and the modulus of resilience are determined in which the energy diagram is shown below, 


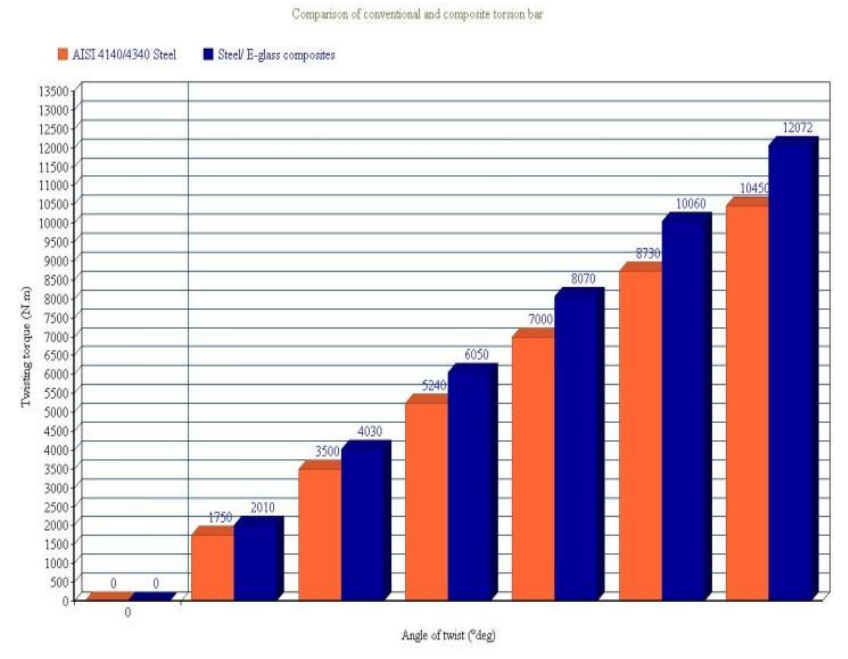

Fig - 3:comparison of twisting moment of conventional and composite torsion bar

The above graph represents the experimental results of the torque- twist relationship of the AISI conventional steel and composite steel/E-glass fibre. In which the comparative result briefly describes that the linear increase upto a point, known as yield or yield stress which is required for the investigation to identify the energy storage of the torsion bar. The yield point results in the angle of twist upto $12^{\circ}$, beyond the angle at some point, the torsion bar gets failed.

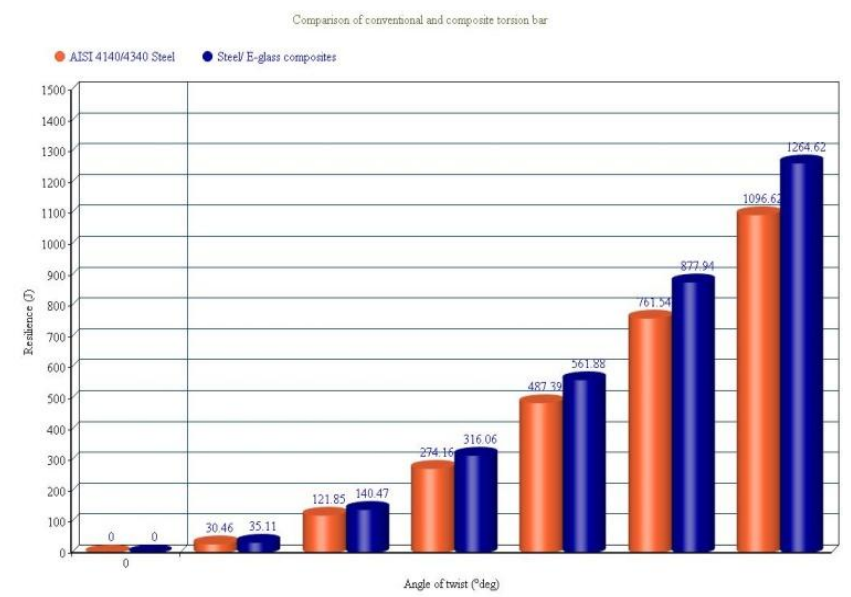

Fig - 4: comparison of resilience properties of conventional and composite torsion bar

The above graph shows the comparison of having maximum energy sustained by composite torsion bar which is more than that of conventional steel torsion bar. It represents the modulus of resilience or otherwise known as proof resilience of the material.

Hence the maximum energy storage absorbing as well releasing energy of the Steel/E-glass composite fibre is identified when it is deformed elastically and upon unloading respectively.

\section{CONCLUSIONS}

As it is a high stressed parts, by introducing a composite structure having maximum energy which will increase the lifetime of the torsion bar used upon two dynamic perspectives, such as riding and handling of vehicle

This study reveals that the composite steel bar can store more energy which will obtain even at higher efficiency, when $\theta=12^{\circ}$ (angle of twist) while comparing with conventional steel torsion bar.

\section{REFERENCES}

[1]. T. Ram Mohan Rao*, G. VenkataRao, k.SreenivasaRao\& A. Purushottam- "Analysis Of Passive And Semi Active Controlled Suspension Systems For Ride Comfort In An Omnibus Passing Over A Speed Bump". Ijrrasvol5,(2010), pp 7- 17.

[2]. P.H. Cronje, P.S. Els - "Improving off-road vehicle handling using an active anti-roll bar". Elsevier Journal of Terramechanicsvol 47, year (2010), pp 179-189

[3]. VinkoMoilnika, NenadGubeljak, JožefPredan- ", Influence of presetting on fatigue lifetime of torsion bars". Elsevier Procedia Engineering vol 10, year (2011), pp 213218

[4]. M. Cerit, E. Nart, K. Genel- " Investigation into effect of rubber bushing on stress distribution and fatigue behaviour of anti-roll bar". Elsevier Engineering Failure Analysis vol 17, year (2010), pp 1019-1027

[5]. E. Mahdi, A.M.S. Hamouda - "An experimental investigation into mechanical behaviour of hybrid and nonhybrid composite semi-elliptical springs". Elsevier Materials and Design vol 52, year (2013), pp 504-513

[6]. Kazuhiro Saitou, NaesungLyu, Jungkap Park, Hiroyuki Urabe, Hiroyuki Tokunaga, Proceedings of IMECE (2006).

[7]. Zhang Jin-qiu, PengZhi-zhao*, Zhang Lei, Zhang Yu "A Review on Energy-Regenerative SuspensionSystems for Vehicles"Proceedings of the World Congress on Engineering 2013 VolIII,July 3 - 5, 2013, London, U.K.

[8]. Mr. BalasahebGadade, Prof. Dr. R.G.Todkar, Mr. Swapnil S. Kulkarni, "Structural Analysis For Suspension Arm For Identifying Areas Of Improvement Over Design". E-ISSN2249-8974vol 2, (2013), pp 132-133

[9]. Gerald R. Kress, Paolo A. Ermanni, "Cfrp Torsion Bar: Load Introduction Problem". 16th International Conference on Composite Materials

[10]. Filizcivigin, “Analysis of Composite Bars In Torsion”, (2005). 